\title{
Determination of the Mohr-Coulomb Material Parameters for Concrete under Indirect Tensile Test
}

\author{
Selimir LELOVIĆ, Dejan VASOVIĆ, Dragoslav STOJIĆ
}

\begin{abstract}
This paper presents determination of the Mohr-Coulomb material parameters for concrete under indirect tensile testing, design of experiments and numerical simulations. Experiments are designed to control input variables associated with inhomogeneous starting material, sample preparation and testing equipment. Statistical analysis of the experimental data is applied in order to correlate material's deformational behaviour with change in cement content. Presented paper discusses a simple method, based on experimental and theoretical framework, to determine two material parameters for concrete: cohesion (c) and angle of internal friction $(\phi)$ from indirect tensile test. Cohesion is obtained from experimental results using elastic and plastic theory of concrete deformation. Prandtl's theory is applied to obtain the angle of internal friction from measured bearing capacity and cohesion. Numerical analysis by finite-element method is used for verification of experimental results, employing step-by-step integration procedure for solving the boundary value problem.
\end{abstract}

Keywords: angle of internal friction; cohesion; concrete; finite element method (FEM); indirect tensile strength; Mohr-Coulomb

\section{INTRODUCTION}

It is a difficult task to control many variables associated with the material and testing equipment in order to describe deformational behaviour of real material. For that reason, it is desirable to repeat measurements in order to apply statistical distribution to experimental results.

Plain concrete is a non-homogeneous mixture of coarse gravel particles, finer sand particles, Portland cement, water and admixtures. Strength gain of concrete is a time-depending process, usually determined in 28 days, and is a very important parameter of the material. In terms of mechanical properties, concrete behaves as a brittle ceramic material. Concrete exhibits low tensile strength compared with its very high compressive strength $[1,2]$. Because of its anisotropic response to outside load, weak in tension, concrete is extensively used as compressive material in structural applications [3]. Its materials response to outside mechanical disturbance is dominated by the following mechanisms: elastic deformation, plastic flow in early stages [4] followed by the initiation and propagation of micro-cracks [5].

In situations where compression induced tension plays a role, such as the split cylinder test, mechanics of plastic deformation may be applied to describe the compression part while fracture mechanics may be applied to describe the induced reactive tension [6]. In order to describe plastic behaviour of concrete, models based on either elasticperfectly plastic material [7] or elastic-plastic material with strain hardening [8] were created. Microstructural observations were made to visualize the structure in order to explain the behaviour of the plain concrete [9]. Various synchrotron radiation laboratory based techniques were used to characterize cement-based material [10]. Application of non-destructive techniques (such as X-ray tomography and ultrasonic imaging) was reported to visualize inclusions in concrete samples [11]. CT scanning was used for density profiles and distribution of air pockets for statistical investigation of materials properties [12]. CT scan showed that air content of concrete was different between top, middle and bottom part of a concrete element.

Work by Bazant et al. [13] presented an attempt to estimate cumulative probability that concrete sample would fail under given load. Weibull statistical model was used to describe size effect of cracks in brittle material. As indicated in the paper, attempt was made to combine the reliability theory with fracture mechanics. Two phases were observed synergistically: crack initiation phase treated with statistics (from reliability theory) and crack propagation phase assumed as the energy part (described as fracture nonlinearity).

An interesting investigation was made in order to understand where initial micro-cracks form. Applying moderate external load caused micro-cracks formation at the interface between the coarse gravel particles and cement paste [14]. Under increased load cracks started to coalesce to form large macro-cracks and to propagate.

Published experimental results [15] for uni-axial compression stress $\sigma$ as a function of axial deformation $\varepsilon_{a}^{2}$ for concrete indicated that plastic hardening occurs at first followed by plastic softening. Justification for using concrete as perfectly plastic material came from Chen [16] who considered perfectly plastic material to be applicable for certain class of problems in mechanics. He described the argument as an "idealization which contains the essential features of certain material behaviour: the tangent modulus when loading in the plastic range is small compared with the elastic modulus, and the unloading response is elastic. Further, the strain level of interest in the problem determines the choice of flow stress. Thus, in a sense, this perfectly plastic flow stress represents a somewhat averaging work-hardening or work-softening of the material over the field of flow". Results published in the literature $[17,18]$ further illustrate the above mentioned point.

The determination of tensile strength by splitting cylindrical concrete sample is described in standard ASTM procedure [19].

According to the elasticity theory [20], the nominal tensile strength of the split tension specimens is defined as

$f_{\mathrm{st}}=\frac{2 P_{\mathrm{max}}}{\pi \cdot b \cdot t}$

where $P_{\max }$ is the maximum load reached during the test, $b$ is the specimen width and $t$ is the specimen depth. 


\section{DESIGN OF EXPERIMENTS}

As mentioned, experiments are designed to control variables associated with sample preparation and with testing equipment. Four series of concrete samples with ten samples in each are made. Testing is performed in the Laboratory at the Faculty for Civil Engineering, University of Belgrade. Hydraulic press is used with capacity of 200 tons, equipped with two inductive sensors (LVDT) calibrated to 1 micron resolution. Automatic acquisition of data is performed with capability of 20 to 40 data points per second.
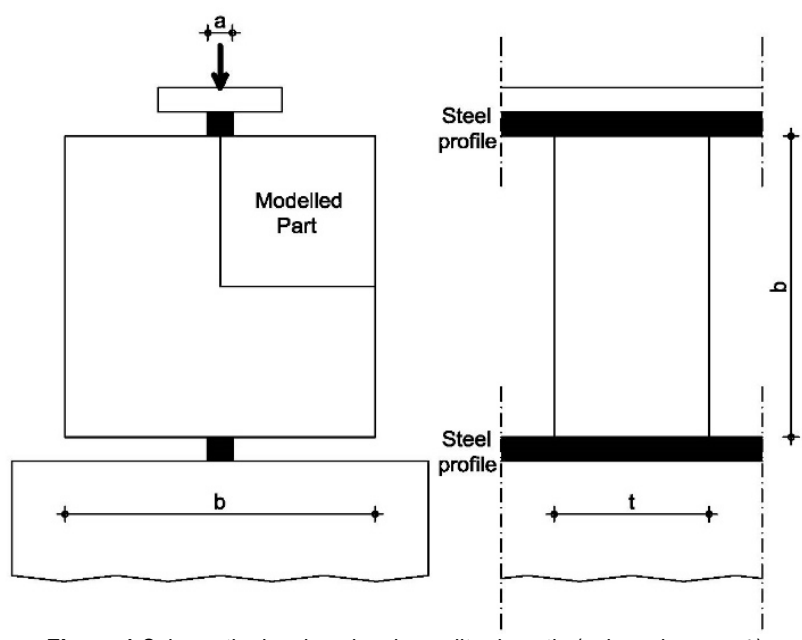

Figure 1 Schematic drawing showing split prismatic (cube, when $t=b$ ) specimens test arrangement

Each concrete sample series consisted of 10 samples. In the same way, other series C-40, C-50 and C-60 are measured. Samples within one series are divided so that first three samples are measured for compressive strength. Remaining samples are divided into two sub-groups for the indirect tensile test (Brazilian test): wooden strip is applied to one sub-group while the rest are tested without wooden strip. Reason for removing the wooden strip is to try to measure concrete displacement as accurately as possible. Wooden strip is affecting concrete displacement data. On the other hand, wooden strip usage is beneficial in measuring ultimate load because it reduced standard deviation.

Fig. 2 shows a steel square bar cross section of $12 \times 12$ $\mathrm{mm}$. In this particular setup (sample C30-5) there is no wooden strip.

Table 1 Experimental measurements as recorded during the Indirect Tensile

\begin{tabular}{|c|c|c|c|}
\multicolumn{4}{|c}{ Test (Brazilian test) } \\
\hline \multirow{2}{*}{ Sample } & $\begin{array}{c}\text { Force } \\
P / \mathrm{kN}\end{array}$ & $\begin{array}{c}\text { Displacement } \\
d / \mathrm{mm}\end{array}$ \\
\hline \multirow{3}{*}{$\begin{array}{c}\text { Without } \\
\text { wooden strip }\end{array}$} & $\mathrm{C} 30-5$ & 106,749 & 0,4973 \\
\cline { 2 - 4 } & $\mathrm{C} 30-6$ & 117,046 & 0,4411 \\
\cline { 2 - 4 } & $\mathrm{C} 30-7$ & 96,348 & 0,3663 \\
\hline \multirow{3}{*}{$\begin{array}{c}\text { With wooden } \\
\text { strip }\end{array}$} & $\mathrm{C} 30-4$ & 96,963 & 1,5460 \\
\cline { 2 - 4 } & $\mathrm{C} 30-8$ & 106,5 & 1,3137 \\
\cline { 2 - 4 } & $\mathrm{C} 30-9$ & 116,747 & 1,7864 \\
\cline { 2 - 4 } & $\mathrm{C} 30-10$ & 103,717 & 1,5388 \\
\hline
\end{tabular}

Average values of measured quantities are: a) for samples without wooden strip, ultimate force is $106,7 \mathrm{kN}$ while displacement is $0,435 \mathrm{~mm}$, and b) for samples with wooden strip, ultimate force is $105,9 \mathrm{kN}$ and displacement is $1,546 \mathrm{~mm}$. Loading rate is about $4,5 \mathrm{kN} / \mathrm{s}$ and displacement rate is about $0,022 \mathrm{~mm} / \mathrm{s}$.

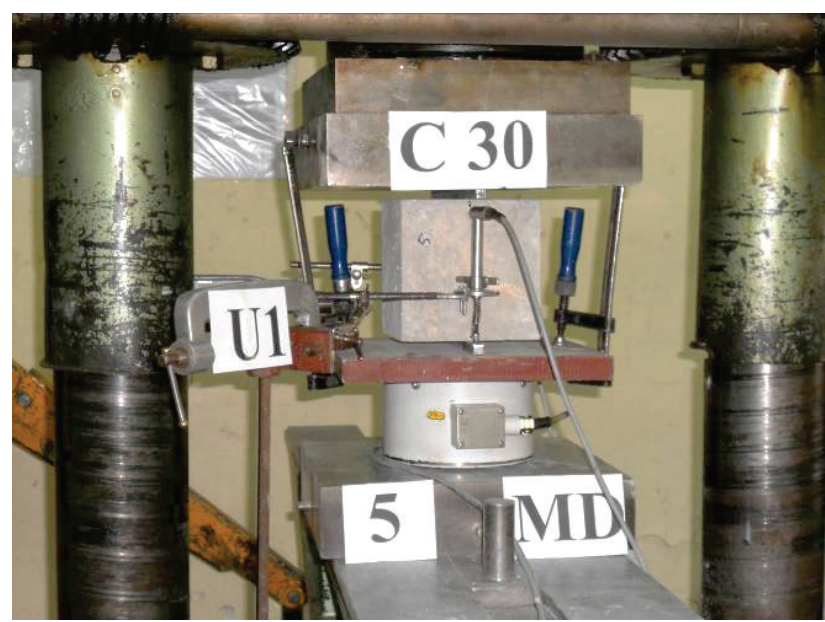

(a)

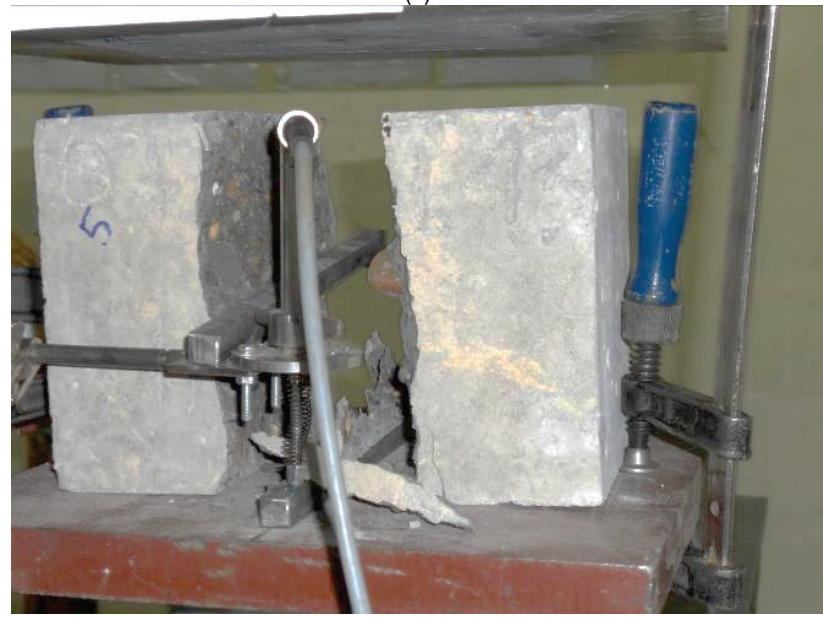

(b)

Figure 2 a) Experimental setup for Brazilian test, b) Broken sample C30-5

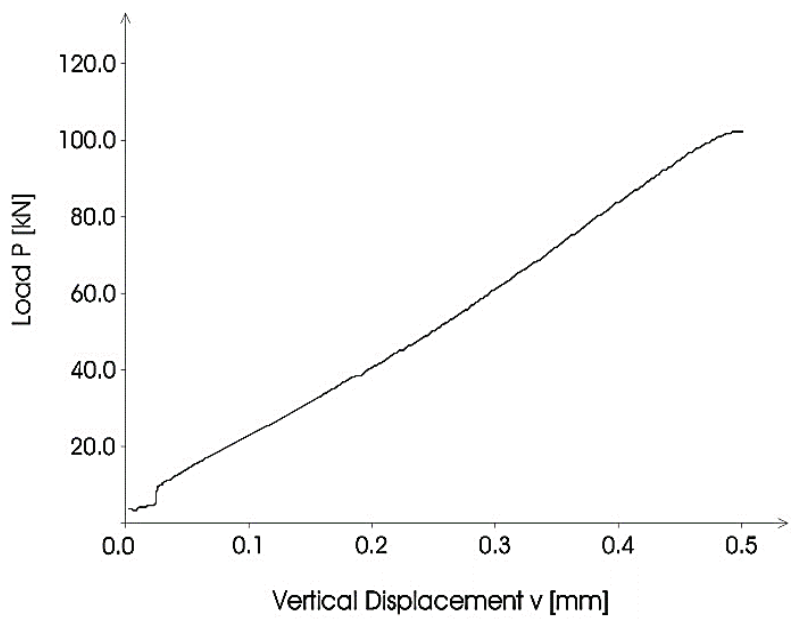

Figure 3 Indirect tensile test measurement data for sample C30-5 (shown in Fig. 2), load vs. displacement

Fig. 3 shows material response to the applied load for sample C30-5. At the peak of applied load, sudden brittle fracture occurred dominated by fast propagation of cracks at the weakest point; sample broke in two parts as shown in Fig. 2 b. 
Table 2 Summary of results for concrete samples tested for compressive and nominal tensile strength

\begin{tabular}{|c|c|c|c|}
\hline $\begin{array}{c}\text { Concrete } \\
\text { Series }\end{array}$ & $\begin{array}{c}\text { Compressive Stress } \\
f_{\mathrm{c}} / \mathrm{MPa}\end{array}$ & $\begin{array}{c}\text { Tensile Stress } \\
f_{\text {st }} / \mathrm{MPa}\end{array}$ & $\begin{array}{c}\text { Factor } \\
\alpha\end{array}$ \\
\hline C-30 & 36,31 & 3,02 & 0,28 \\
\hline C-40 & 40,06 & 3,56 & 0,31 \\
\hline C-50 & 36,50 & 3,79 & 0,35 \\
\hline C-60 & 52,79 & 4,49 & 0,32 \\
\hline
\end{tabular}

Tab. 2 shows summary of testing results for concrete series $\mathrm{C}$, where nominal tensile strength is roughly about $10 \%$ of the compressive strength. As Tab. 2 shows, the mean compressive strength $\left(\sigma_{\text {comp }}\right)$ is $36,3 \mathrm{MPa}$ for concrete C-30, $40 \mathrm{MPa}$ for series C-40, 36,5 MPa for series C-50 and $52,8 \mathrm{MPa}$ for $\mathrm{C}-60$. These measurements show that there are deviations in sample making procedure probably because of manmade error.

Based on results generated for concrete series $\mathrm{C}$, there are the following observations:

- Functional dependence between compressive and tensile strength expressed in mathematical formula $f_{\text {st }}$ $=\alpha\left(f_{\mathrm{c}}\right)^{2 / 3}$, with expected value for $\alpha=0,3$ [21], matches well with the experimental results for all concrete samples in series $C$, where $\alpha$ is very close to 0,3 .

- There is increase in both compressive and tensile strength with increase in cement content (as shown with higher number for concrete series).

- Statistical analysis showed C-50 sample series as an outlier: compared with sample series C-40 observed decrease in compressive strength while exhibiting small increase in tensile strength. It is possible that exhibited anomaly in sample series C-50 is caused by inhomogeneity in the sample preparation.

Based on presented experimental results for concrete series $\mathrm{C}$, there are the following conclusions:

- Applied compressive and tensile loads act differently on the pre-existing micro-cracks in concrete samples. Compressive load tends to oppose the crack propagation, closing the tip of crack. Therefore, significant increase in compressive load is required in order to generate new cracks. On the other hand, applied tensile load tends to open the tip of pre-existing micro-cracks in concrete samples.

- From statistical point of view, orientation probability distribution and size probability distribution of initial cracks may govern the materials response to applied load. As mentioned in the introduction, propagation phase for applied tensile load may determine the dynamics of materials response while for compressive load initiation of new crack may be more crucial.

\section{$3 \quad$ MOHR-COULOMB YIELD CONDITION}

In the following sections, compressive stress and strains are considered positive. The Mohr-Coulomb yield function is typically used to describe geomaterials as it has a dependence on the pressure [22, 23, 24].

For cohesionless materials, the Mohr-Coulomb yield criterion can be described mathematically in terms of the principal stresses:

$\sin \phi=\frac{\sigma_{1}-\sigma_{3}}{\sigma_{1}+\sigma_{3}}$ where $\phi$ is the friction angle, $\sigma_{1}$ and $\sigma_{3}$ are the maximum and minimum principal stresses respectively. In order to include the cohesion in the frictional criteria, the cohesion effect is replaced with a corresponding normal stress $\sigma_{\mathrm{C}}$, the boundary equilibrium condition can be written in the same form as for incoherent material:

$\sin \phi=\frac{\sigma_{1}^{*}-\sigma_{3}^{*}}{\sigma_{1}^{*}+\sigma_{3}^{*}}$

where: $\sigma_{1}^{*}$ and $\sigma_{3}^{*}$ are corresponding main stresses, equal to:

$$
\begin{aligned}
& \sigma_{1}^{*}=\sigma_{1}+c \cdot \cot \phi \\
& \sigma_{3}^{*}=\sigma_{3}+c \cdot \cot \phi
\end{aligned}
$$

Entering the values of the corresponding main stresses given by expressions (4), into expression (3), the condition of the boundary equilibrium can be written in the form:

$$
\frac{\sigma_{1}-\sigma_{3}}{2} \cdot \frac{1}{\cos \phi}-\frac{\sigma_{1}+\sigma_{3}}{2} \cdot \tan \phi=c
$$

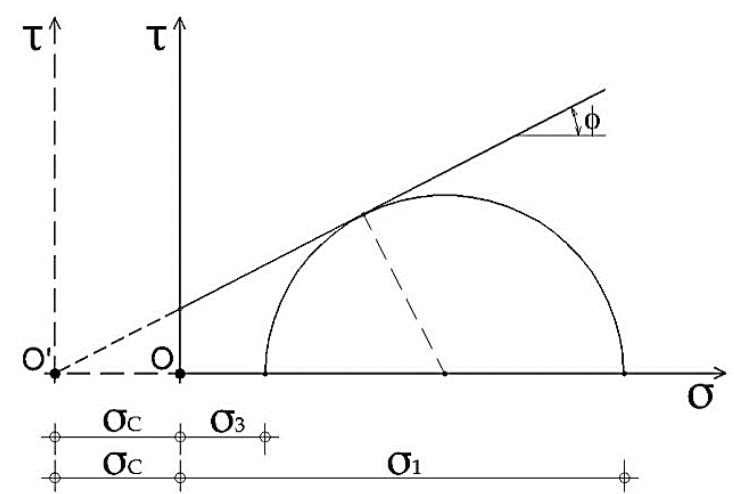

Figure 4 Graphic representation of a translation of the normal principal stresses in the two-dimensional stress space

\section{DETERMINATION OF C AND $\phi$ FROM INDIRECT TENSILE TEST}

Nielsen and Hoang [25], in their book, describe the theory of limit analysis and concrete plasticity in plain concrete, and suggest that it is possible to use the limit analysis to the indirect tensile test of concrete. Considering the problem of plain strain metal punching by the method of classical plasticity theory, Prandtl (1920) determined the boundary load for the strip foundation. He assumed the material was weightless. The exact collapse pressure of a strip footing resting on a Mohr-Coulomb material with no overburden pressure is:

$$
q_{\mathrm{f}}=c \cdot\left(\mathrm{e}^{\pi \cdot \tan \phi} \cdot \tan ^{2}\left(\frac{\pi}{4}+\frac{\phi}{2}\right)-1\right) \cdot \cot \phi
$$

Assuming that indirect tensile strength $\left(f_{\mathrm{st}}\right)$ is equal to a corresponding normal stress as a consequence of cohesion $\sigma_{\mathrm{C}}[26]$, and that the boundary line loading can be determined using Prandtl's equation, the cohesion and the 
angle of internal friction can be determined; two expressions are obtained to determine:

$c=f_{\mathrm{st}} \cdot \tan \phi$

$\mathrm{e}^{\pi \cdot \tan \phi} \cdot \tan ^{2}\left(\frac{\pi}{4}+\frac{\phi}{2}\right)=1+\frac{\pi}{2} \cdot \frac{b}{a}$

where $b / a$ is the ratio of the specimen width to the distributed-load width, as depicted in Fig. 1.

Experimentally measured values for bearing capacity $\mathrm{q}_{\mathrm{f}}$ and for cohesion $\mathrm{c}$, enable the calculation of the angle of internal friction. For each particular concrete mixture plasticity parameters are defined: cohesion from indirect tensile test and the angle of internal friction are calculated using Prandtl's formula.

\section{NUMERICAL ANALYSIS OF CONCRETE SPLIT CUBE TEST}

An incremental finite element method is used for nonlinear analysis of the problem. The basic equations of the incrementally-iterative procedure with the applied algorithm for the integration of constituent equations are given in Reference [27]. Integration of elasto-plastic constitutive relations is done with return mapping algorithm as described by Simo and Ortiz [28].

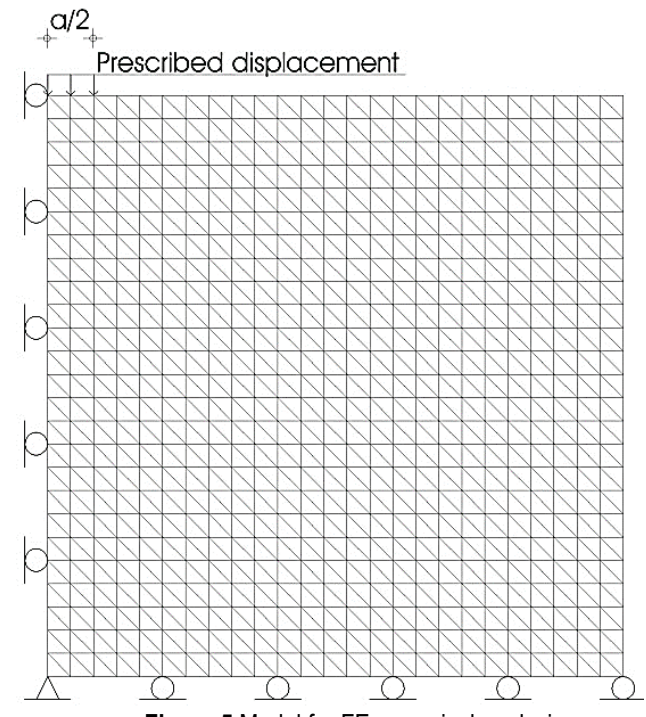

Figure 5 Model for FE numerical analysis

Described constitutive model is implemented in the new discretized finite element (FE) code. Bearing capacity for a squared concrete sample is considered. Application of the finite element code in numerical analysis of the concrete splitting test is presented. Simulation is done by displacement-controlled method as presented in Fig. 5. Due to symmetry of the problem, a quarter of the domain in numerical analysis is considered with constant strain triangular elements under plane strain conditions.

The geometry of the boundary value problem is presented in Fig. 5. Width of the half space was six times the width of the bearing plate and depth was also six times the width of the bearing plate. Reflected boundary was on the side and down on the bottom. Mesh used for the finite element modelling had two elements under half of the footing, with 50 elements along the width and 50 elements for the depth.
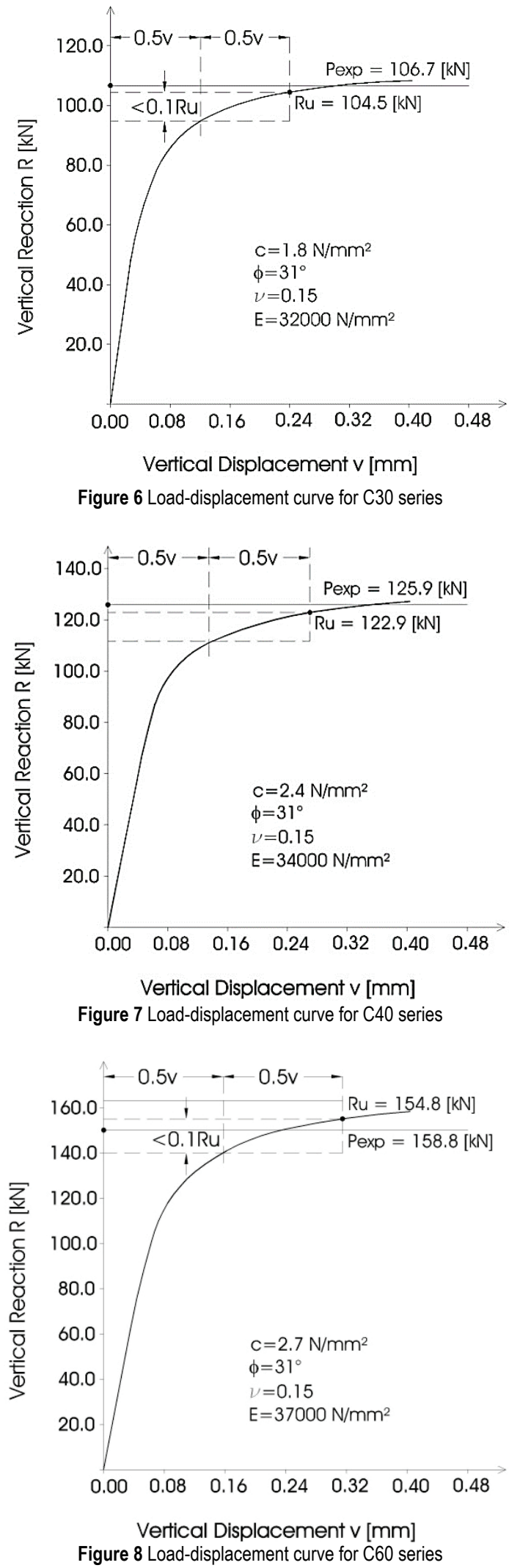

Hansen's criterion is used to determine critical loading from the load-displacement curve [29, 30]. As indicated in Figs. 7 and 8, load corresponding to half the displacement is very close to the failure loading (load difference less than $10 \%$ ). 
Tab. 3 shows summary of the results for maximum indirect tensile load measured experimentally and numerical data from the Mohr-Coulomb model. The comparison between experimental results and numerical data from the model, showed small error of up to $2,5 \%$ when Hansen's criterion is used to determine critical loading.

Table 3 Summary of experimental and numerical results for ultimate load for concrete series

\begin{tabular}{|c|c|c|c|}
\hline $\begin{array}{c}\text { Concrete } \\
\text { Series }\end{array}$ & $\begin{array}{c}\text { Experimental data } \\
P_{\exp } \max ^{\prime} / \mathrm{kN}\end{array}$ & $\begin{array}{c}\text { Numerical data } \\
P_{\text {num }}{ }^{\max } / \mathrm{kN}\end{array}$ & $\begin{array}{c}\text { Numerical } \\
\text { Error } / \%\end{array}$ \\
\hline C-30 & 106,70 & 104,50 & 2,06 \\
\hline C-40 & 125,90 & 122,90 & 2,38 \\
\hline C-60 & 158,80 & 154,80 & 2,52 \\
\hline
\end{tabular}

As presented in Figs. 6, 7 and 8, all three curves showed similar trend: initial elastic region to reach plastic deformation, then starts the middle section with bend and change in slope and finally, the end of testing is reached. Simulation curves for C-30, C-40 and C-60 at $0,5 \mathrm{~mm}$ displacement, showed load values of $107,4 \mathrm{kN}, 123,8 \mathrm{kN}$ and $152,6 \mathrm{kN}$, respectively. Compared with experimental results of $P_{\max }=106,7 ; 125,9 ; 158,8 \mathrm{kN}$ for those three sample series show excellent match for the load bearing capacity.

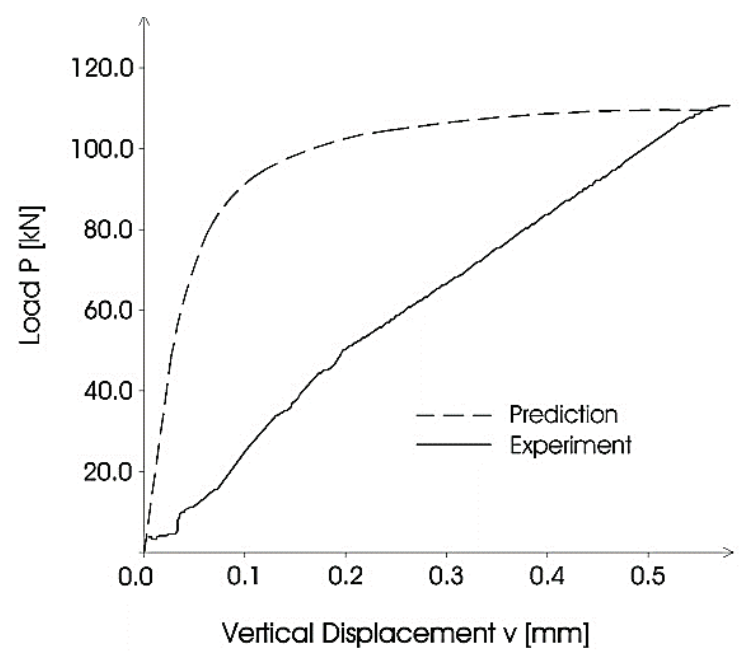

Figure 9 Load-displacement curves for C30 sample series obtained with experiment and numerical analysis

While bearing capacity obtained using numerical modelling and experimental measurements showed remarkably good correlation, shape of numerical modelling curve deviated from experimentally measured curve, as shown in Fig. 9. Materials behaviour is complex under compression induced tensile load, first point is one may consider concrete as an inhomogeneous material and second point to consider dynamic effects upon loading.

It is possible to look at the deviation along the lines indicated by Prandtl, firstly considering concrete as inhomogeneous material and secondly, considering time factor. Concrete is material for which Young's modulus changes during testing while time factor is given through linear dependence of load on the logarithm of strain rate: "an inhomogeneous material structure. One suspects that for very irregularly constituted brittle solids (stones, concrete, weakly fired clay) such phenomena can be really observed. For solids of this kind it may be possible to think of alternate concepts ... If one assumes a stacking of beams, $\ldots$, then the properties of stone-like solids for which Young's modulus decreases under tension would be realized and might be possible to explore the hysteresisand flow-phenomena of such materials[31]". This classic paper indicates the stress dependence formula on the logarithm of the strain rate as follows: $\sigma_{0}=A+B \times \ln (c)$, where $\mathrm{c}$ is the strain rate.

Many other authors considered time as the factor affecting tensile properties of concrete. For example, experimental and numerical testing of concrete showed that there is significant influence of loading rate on tensile properties: tensile resistance increases with increasing strain rate in accordance with the above mentioned formula $[32,33]$. As already pointed out, establishment of equilibrium requires minimum time for two steps: stress to build up and time for the decay effect.

In this paper, loading and displacement rates are about $4,5 \mathrm{kN} / \mathrm{s}$ and $0,022 \mathrm{~mm} / \mathrm{s}$, respectively, for the sample C305 . These rates indicate that there may be enough time for the decay effect before the next load increase, therefore at each step quasi-static splitting equilibrium is reached. Experimental load displacement curve, as shown in Figure 9, indicates the same time increment for load and displacement. Furthermore, the effect of strain rate on tensile strength of concrete is associated with the dynamic increase factor or DIF, the ratio of dynamic to static strength [34]. For example, for the reported loading rate of $2,5 \mathrm{kN} / \mathrm{s}$, which is in the range of our experimental values, corresponding strain rate of about $2,5 \times 10^{-6}\left(\mathrm{~s}^{-1}\right)$, DIF values increased about $10 \%$. Results are explained from thermodynamic point of view, with Arrhenius type strain behaviour, the activation energy is in the negative exponent of strain rate, which then leads to stress as a logarithmic function of the strain rate. Again, similar functional dependence is as described by Prandtl in his original paper.

FE analysis of concrete split cylinder test given by Chen in Reference 1 used Drucker-Prager plasticity model. Initially, crack formed at the edge of the loading plate. As the bearing plate is pushed down into the concrete sample, changes in distribution and ratio between vertical and horizontal stresses were observed in their profiles. The point of fracture is reached when crack reached reflected boundary, and when the wedge shaped region is formed. It appeared that sample fractured prematurely, crack only reached reflected boundary and did not propagate to reach bottom plate. In order to have a better understanding of how the plastic deformation from the section under the bearing plate affected crack propagation, horizontal displacement profiles were observed in the column right next to the footing edge. Horizontal displacements follow gradual yielding contours propagation from the edge of bearing plate towards reflected boundary on the left and then down towards reflected boundary on the bottom.

Deformation shown in Fig. 9, is somewhat similar to modes predicted by linear dynamic analysis [35]. According to the mathematical functions describing relationship between vertical and horizontal stresses and depth of the cylinder, given by the linear theory, compressive stress is high in the region right under the bearing plate, while the tensile stress is high close to the centre of the cylinder. Results of the linear analysis indicated crack initiation to start at the centre of the 
cylinder. On the other hand, results of the dynamic analysis, suggested initiation of the first crack to start at a distance from the top of approximately $0,2 \times D$ (diameter of the cylinder), with subsequent propagation in both directions along the vertical centreline of the cylinder toward the top and bottom surfaces.

\section{NUMERICAL EXAMPLE OF SPLITTING TEST ON A CONCRETE PRISM}

Indirect tensile test described by Rocco et al. [36] is simulated in the numerical application. Tab. 4 shows STP sample series with four different $b \times t$ dimensions, bearing ratio of $a / b$ equal to 0,08 , compressive strength $f_{\mathrm{c}}=38$ $\mathrm{MPa}$, Modulus of elasticity $E=31 \mathrm{GPa}$. As stated, load is applied by two $3 \mathrm{~mm}$ thick plywood strips interposed between the specimen and the machine platens. Since deformation is not given, dashed flat lines are used to indicate maximum load as shown in Tab. 4.

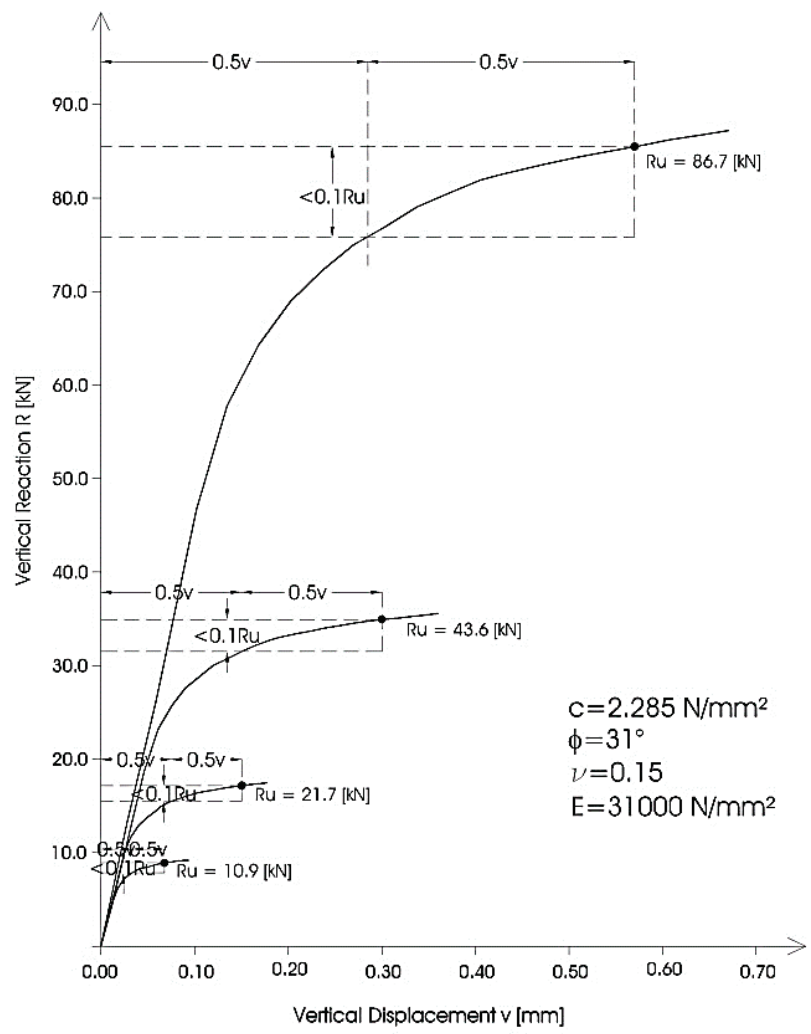

Figure 10 Load-displacement curves for sample series obtained with numerical modelling and measurements by Rocco et al. Values 0,5 of vertical displacement indicate the criterion to determine ultimate value $<0,1 R u[30]$.

Load displacement curves for STP sample series obtained with FE numerical modelling are compared with measurements by Rocco et al. [36] and the comparison is shown in Fig. 10. FE model for STP samples showed very small load error compared with maximum load reported by Rocco. FE model for STP-300 showed that load of $86,7 \mathrm{kN}$ is reached at $0,57 \mathrm{~mm}$ displacement. FEM modelling results for STP samples with dimensions of $300 \times 50 \mathrm{~mm}$ are similar to values for C-30 series with dimensions of $150 \times 150 \mathrm{~mm}$, also reaching $\max$ load at $0,5 \mathrm{~mm}$ displacements. It should be noted that the compressive strengths of the C-30 and the corresponding sample STP150 are approximately equal.
Fig. 11 is presented to compare FEM modelling from the present work with modelling reported in literature and experimental value of Rocco et al. [36].

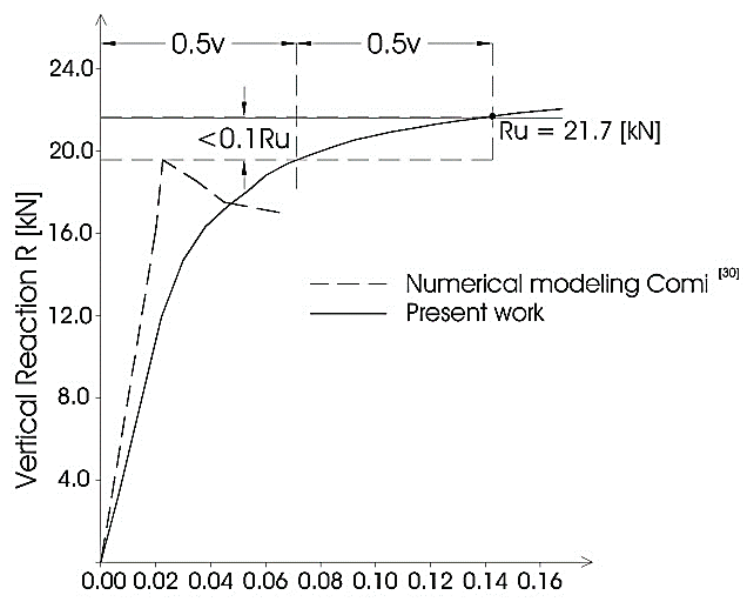

Vertical Displacement v [mm]

Figure 11 Load-displacement curves for STP-75 sample series with $a / b$ equal to 0.08 , obtained with measurements by Rocco et al. [36], FE numerical modelling by Comi et. al., [37] and this work.

As indicated in Tab. 4, FEM model showed that max load of $23,36 \mathrm{kN}$ is reached at $0,135 \mathrm{~mm}$ displacement, while maximum load reported by Rocco is $21,6 \mathrm{kN}$. Comi and Perego used the same experimental example to test their FEM model [37]. FEM modelling curve for STP-75 sample for the narrow loading strip ( $a / b$ equal to 0,08 ), as presented in Fig. 11 showed linear increase with peak load at about $19,5 \mathrm{kN}$ obtained at 0,026 mm displacement (peak strain is $0,034 \%$ ), followed by ductile softening after the peak. For the same experimental example, similar load displacement curve is obtained by FEM modelling using thermodynamic approach by Nguyen and Houlsby [38]. Tensile and compressive damage contours are presented to illustrate the failure process at different loading stages. Failure damage is localized underneath the load bearing strip.

Table 4 Specimen geometry and results of splitting tests described by Rocco et al. [36] and present FE modelling for the width bearing strip $a / b=0,08$.

\begin{tabular}{|c|c|c|c|c|c|}
\hline Specimen & $\begin{array}{c}\text { Dimensions } \\
b \times t / \mathrm{mm}\end{array}$ & $\begin{array}{c}\text { Tensile } \\
\text { strength } \\
f_{\text {st }} / \mathrm{MPa}\end{array}$ & $\begin{array}{c}\text { Exp. } \\
\text { data } \\
P_{\max }^{\exp } \\
/ \mathrm{kN}\end{array}$ & $\begin{array}{c}\text { Num. } \\
\text { data } \\
P_{\max }^{\text {num }} \\
/ \mathrm{kN}\end{array}$ & $\begin{array}{c}\text { Num. } \\
\text { Error } \\
/ \%\end{array}$ \\
\hline STP-300 & $300 \times 50$ & 3,89 & 91,60 & 86,70 & 5,35 \\
\hline STP-150 & $150 \times 50$ & 3,78 & 44,51 & 43,80 & 1,60 \\
\hline STP-75 & $75 \times 50$ & 3,66 & 21,55 & 21,70 & 0,70 \\
\hline STP-37 & $37 \times 50$ & 3,88 & 11,27 & 10,90 & 6,84 \\
\hline
\end{tabular}

Numerical modelling curve in the present work is obtained with only 4 material parameters: $E$, $v$, cohesion $c$ and angle of internal friction $\phi$. Load deformation curve obtained with our FE model is shifted to the right compared with Comi, almost doubling displacements. It appears that the shape of our FE model load displacement curve accurately describes deformation behaviour of concrete under induced tensile load. 


\section{CONCLUSION}

Tensile strength of the concrete is a property often determined indirectly because it is extremely difficult to perform direct tensile test experiment and to obtain homogeneous tensile state. Concrete is a brittle material exhibiting tensile strength lower by order of magnitude compared with its high compressive strength. Experiments are designed to control input variables associated with concrete's inhomogeneous starting material, sample preparation and testing equipment. Destructive measurements are performed on series of concrete samples under compressive and tensile load. Statistical analysis is applied to experimental results in attempt to correlate increase in compressive and tensile strength with increase in cement content. Cohesion is the only materials parameter obtained from experimental results from the indirect tensile testing. Then, Prandtl's theory is used to calculate the angle of internal friction. Both material parameters are used in the linear Mohr-Coulomb model for numerical analysis of concrete.

\section{REFERENCES}

[1] Neville, A. (1963). Properties of Concrete, Wiley.

[2] Chen, W. F. (1982). Plasticity in Reinforced Concrete, McGraw Hill.

[3] Chen, A. C. T. \& Chen, W. F. (1975). Constitutive Relations for Concrete. J. Engrg. Mech. Div., ASCE, 101(4), 465-481.

[4] Lubliner, J., Oliver, J., Oller, S., \& Onate, E. (1989). A Plastic Damage Model for Concrete. Int. J. Solids Structure, 25(3), 299-326. https://doi.org/10.1016/0020-7683(89)90050-4

[5] Krajcinovic, D. (1985). Continuous Damage Mechanics Revisited Basic Concepts and Definitions. J. Appl. Mechanics, 52(4), 829-834. https://doi.org/10.1115/1.3169154

[6] Lubliner, J. (1990). Plasticity Theory, Mac Millan, New York.

[7] Vukelic, S. (1981). Analysis of Mechanical Deformation of Concrete, PhD Thesis, Belgrade.

[8] Hu, H. T. \& Schnobrich, W. C. (1989). Constitutive modeling of concrete by using non associated plasticity. Journal of Materials in Civil Engineering, 1(4), 199-215. https://doi.org/10.1061/(ASCE)0899-1561(1989)1:4(199)

[9] Mehta, P. K. \& Monteiro, P. J. (1993). Concrete: structure, properties and materials, Prentice Hall.

[10] Chae, S. R., Moon, J., Yoon, S., Bae, S., Levitz, P., Winarski, R., \& Monteriro, P. J. (2013). Advanced Nanoscale Characterization of cement based materials using X-ray synchrotron radiation a review. International Journal of Concrete Structures and Materials, 7, 95-111. https://doi.org/10.1007/s40069-013-0036-1

[11] Daigle, M., Fratta, D., \& Wang, L. B. (2005). Ultrasonic and X-ray Tomographic Imaging of Highly Contrasting Inclusions in Concrete Specimens. GeoFrontier Conference, Austin TX. https://doi.org/10.1061/40785(164)40

[12] Caliskan, S. (2007). Examining Concrete Cores by Nondestructive Techniques. $4^{\text {th }}$ Middle East NDT Conference and Exhibition, Kingdom of Bahrain.

[13] Bazant, Z. P., Pang, S. D., Verchovsky, M., Novak, D., \& Pukl, R. (2004). Statistical size effect in quasi brittle materials computation and extreme value theory. Fracture Mechanics of Concrete Structures, Li et al. (eds.), 189-196.

[14] Lowes, L. (1999). Finite Element Modeling of Reinforced Concrete Beam Column Bridge Connections. PhD Thesis, UC Berkeley.
[15] Karsan, I. D., Jirsa, J. O., \& Chen W. F. (1969). Behavior of concrete under compressive loadings. Journal of Structure Division, ASCE, 95(12), 2535-2563.

[16] Chen, W. F. (2007). Limit Analysis and Soil Plasticity, J. Ross Publishing, p. 543.

[17] Gopalaratnam, V. S. \& Shah, S. P. (1985). Softening response of plain concrete in direct tension. ACI Journal, 82, 311-323.

[18] Taquieddin, Z. N. (2008). Elasto-plastic and damage modeling of reinforced concrete. PhD Thesis, Louisiana State University.

[19] Standard ASTM C 496 C39 Splitting Tensile Strength of Cylindrical Concrete Specimens.

[20] Timoshenko, S. P. \& Godier, J. N. (1970) Theory of Elasticity. Third Edition, Mc.Graw-Hill, New York.

[21] (1991). Evaluation of the Time Dependent Behaviour of Concrete, Bulletin d'Information No. 199, Comite European du Beton/Federation Internationale de la Precontrainte, Lausanne.

[22] Christian, J. T., Hagmann, A. J., \& Marr, W. A. (1977). Incremental Plasticity Analysis of Frictional Soils. International Journal for Numerical and Analytical Methods in Geomechanics, 1, 343-375. https://doi.org/10.1002/nag.1610010403

[23] Crisfield, M. A. (1987). Plasticity computations using the Mohr-Coulomb yield criterion. Eng. Comput. 16(4). https://doi.org/10.1108/eb023708

[24] Borst, de R. (1987). Integration of plasticity equations for singular yield functions, Computers and Structures, 26, 823 829.

[25] Nielsen, M. P. \& Hoang, L. C. (2010). Limit Analysis and Concrete Plasticity, $3^{\text {rd }}$ Edition, CRC Press, p. 176.

[26] Anagnostou, G. \& Kovari, K. (1993). Significant Parametres in Elastoplastic Analysis of Underground Openings. Journal of Geotechnical Engineering, 119, 401-419. https://doi.org/10.1061/(ASCE)0733-9410(1993)119:3(401)

[27] Potts, D. M. \& Zdravković, L. (1999). Finite Elements Analysis in Geotechnical Engineering - Theory, Thomas Telford Publishing, London. https://doi.org/10.1680/feaiget.27534

[28] Ortiz M. \& Simo, J. D. (1986). An analysis of a new class of integration algorithms for elastoplastic constitutive relations. International Journal for Numerical Methods in Engineering, 23, 353-366. https://doi.org/10.1002/nme.1620230303

[29] Hansen, J. B. (1970). A Revised and Extended Formula for Bearing Capacity, Danish Geotechnical Institute, Copenhagen, Bulletin No. 28.

[30] Sieffert, J. G. \& Bay-Gress, Ch. (2000). Comparison of European bearing capacity calculation methods for shallow foundations. Proc. Institution of Civil Engineers, 143, 65-74. https://doi.org/10.1680/geng.2000.143.2.65

[31] Prandtl, L. (2011). A Thought Model for the Fracture of Brittle Solids. Zeitschrift für angewandte Mathematik und Mechanik, 13, (1933), 129-133 (Translated by W.G. Knauss, June, Caltech, 105-150).

[32] Lu, Y. \& Song, Z. H. (2012). On the Strain Rate Limits in Dynamic Testing of Concrete Like Heterogeneous Materials. EPJ Web of Conferences, 26, 04035. https://doi.org/10.1051/epjconf/20122604035

[33] Diamaruya, M., Kobayashi, H., \& Nonaka, T. (1997). Impact Tensile Strength and Fracture of Concrete. J. Phys IV France, 7.

[34] Min, F., Yao, Z., \& Hang, T. (2014). Experimental and Numerical Study on Tensile Strength of Concrete under Different Strain Rates. The Scientific World Journal Volume 2014, Article ID 173531, Hindawi Publishing Corp. https://doi.org/10.1155/2014/173531

[35] Tedesco, J. W. (1990). Numerical Analysis of Dynamic Splitting Tensile and Direct Tension Tests. Air Force Report 
(ESL-TR-89-45) Air Force Engineering, Tyndall AFB FL 32403.

[36] Rocco, C., Guinea, G. V., Planes, J., \& Elices, M. (1995).

The Effect of Boundary Conditions on the Cylinder Splitting Strength. Fracture Mechanics of Concrete Structures, Proceedings FRAMCOS-2, ed. by Folker H. Wittmann, AEDIFICA TIO Publishers, D-79104 Frei burg.

[37] Comi, C. \& Perego, U. (2001). Fracture Energy Based Bidissipative Damage Model for Concrete. International Journal of Solids and Structures, 38, 6427-6454. https://doi.org/10.1016/S0020-7683(01)00066-X

[38] Nguyen, G. D. \& Houlsby, G. T. (2008). A Coupled Damage - Plasticity Model for Concrete Based on Thermodynamic Principles Part II non-local Regularization and Numerical Implementation. International Journal for Numerical and Analytical Methods in Geomechanics, 32, 391-413. https://doi.org/10.1002/nag.649

\section{Contact information:}

Selimir LELOVIĆ, Assistant Professor

University of Belgrade

Faculty of Civil Engineering,

Bulevar kralja Aleksandra 73, 11000 Belgrade, Serbia

E-mail: lelovic@grf.rs

Dejan VASOVIĆ, Assistant Professor

University of Belgrade

Faculty of Architecture,

Bulevar kralja Aleksandra 73, 11000 Belgrade, Serbia

E-mail: vasovic@arh.rs

Dragoslav STOJIĆ, Full Professor

University of Niš

Faculty of Civil Engineering and Architecture,

Aleksandra Medvedeva 14, 18000 Niš, Serbia

E-mail: stojic@gaf.ni.ac.rs 